\title{
Gestão territorial e economia social e solidária: uma análise pela reciprocidade
}

\author{
Regional land management and solidarity economy: an analysis by reciprocity
}

Eric Sabourin ${ }^{1}$

\begin{abstract}
Resumo
O artigo trata da contribuição do princípio de reciprocidade para a questão do desenvolvimento sustentável a partir de três enfoques que mobilizam essa noção: a governança dos comuns, a economia solidária e a teoria da reciprocidade. A primeira parte apresenta a qualificação e o papel da reciprocidade nesses três enfoques. A segunda parte desenvolve o diálogo entre essas três propostas teóricas a partir de exemplos contemporâneos de aplicação do princípio de reciprocidade a casos de desenvolvimento territorial sustentável. A conclusão aborda os limites desses enfoques.
\end{abstract}

Palavras-chave: Reciprocidade; Troca; Economia solidária; Desenvolvimento territorial sustentável; Políticas Públicas.

\begin{abstract}
The article discusses the contribution of the principle of reciprocity to the issue of sustainable development, from three approaches that mobilize this notion: the governance of commons; the solidarity economy and the theory of reciprocity. The first part presents the qualification and the role of reciprocity in these three approaches. The second part develops a dialogue between these three theoretical proposals, based on contemporary examples of application of the principle of reciprocity to cases of sustainable regional development. The conclusion examines the limits of these theories.
\end{abstract}

Keywords: Reciprocity; Exchange; Solidarity economy; Sustainable regional development; Public policies.

\section{Introdução}

O artigo propõe um diálogo entre a teoria da reciprocidade e o enfoque do desenvolvimento territorial sustentável, examinando o papel das relações não mercantis inerentes aos territórios.

A história recente no Brasil e os trabalhos de diversos autores nos oferecem exemplos de construção social de territórios ou de revitalização de territórios por meio da economia solidária

\footnotetext{
${ }^{1}$ Doutor em Antropologia. Pesquisador titular do Cirad, Unidade Art-Dev. Professor visitante na Universidade de Brasília no CDS e no Mader. E-mail: sabourin@cirad.fr.
} 
(FRANÇA FILHO, 2006; GAIGER, 2003, 2005; GIRARD, 2007). Este artigo tenta aprofundar o diálogo entre economia social e solidária e desenvolvimento dos territórios, mostrando o diferencial de análise e de explicação que permite o uso da teoria da reciprocidade. Confronta os enfoques da teoria da reciprocidade com a teoria da economia solidária e com aquela da governança dos recursos comuns de Elinor Ostrom.

O que é a reciprocidade? A noção de reciprocidade nas Ciências Sociais foi mobilizada nos anos 1990 por três quadros teóricos que se cruzaram mais recentemente nos 2000: a sociologia econômica aplicada à economia solidária (LAVILLE, 2000; CATTANI, 2003), a governança dos recursos em propriedade comum (OSTROM, 1990, 1998, 2003, 2005) e a renovação da teoria da reciprocidade na antropologia (SCUBLA, 1985; TEMPLE E CHABAL, 1995). O mérito comum a esses três enfoques é oferecer uma leitura teórica das relações sociais, e sobretudo econômicas, que propõe, através do princípio de reciprocidade, uma alternativa à naturalização da lógica de concorrência entre interesses privados, levando a generalização da troca mercantil como modo de regulação da sociedade.

Em etnologia e antropologia, a reciprocidade designou por muito tempo as prestações mútuas de alimentos, de bens e de serviços entre pessoas e entre grupos (THURNWALD, 1932; MALINOWSKI, 1933; MAUSS, 1924/1989), em particular nas sociedades indígenas e camponesas. Lévi-Strauss (1967) pôde, assim, propor um princípio de reciprocidade governando o conjunto das relações e estruturas de parentesco. Do ponto de vista antropológico, o princípio de reciprocidade corresponde, portanto, a um ato reflexivo entre sujeitos, a uma relação intersubjetiva e não somente a uma simples permuta de bens ou de objetos. Foi procurando teorizar sobre a dádiva e a troca que Mauss redescobre o princípio de reciprocidade proposto por Thurnwald (1921/1932) ${ }^{2}$ e Malinowski (1922). Paradoxalmente, procurando colocar a dádiva na origem da troca no Ensaio sobre a Dádiva, Mauss (1924/1989) mostra que a dádiva é oposta à troca mercantil. Mas ele demonstra igualmente, através da formulação da tríplice obrigação dar, receber e retribuir que é a reciprocidade que está no início dos ciclos de dádiva (MAUSS, 1989, p. 185).

Mauss (1931/1968) se deu conta da origem natural das estruturas de reciprocidade nas condições do parentesco original, em particular em termos de exogamia e de filiação. Então, estabeleceu a existência de formas de reciprocidade direta (as relações de reciprocidade binárias, em particular o cara a cara) e indiretas: as relações de reciprocidade ternárias que envolvem mais de dois sujeitos (MAUSS, 1989, p. 128-131).

\footnotetext{
${ }^{2}$ Publicação original em alemão em 1921 (Die Gemeinde der Banaro. Stuttgart: F. Enke, 274. p. 1921).
} 
Lévi-Strauss (1989, p.IX-LII) criticará Mauss por não ter percebido que é a troca e não um sistema qualquer de crenças indígenas (o espírito da dádiva ou o mana) que constitui a estrutura subjacente às três obrigações de "dar, receber e retribuir". Ele critica, na verdade, Mauss por não ter postulado a troca no centro da função simbólica. No entanto, associando aliança e parentesco à tripla obrigação: dar, receber e retribuir, Mauss traçou um programa que Lévi-Strauss retoma nas Estruturas elementares do parentesco (1967), ordenando as relações de parentesco ao princípio da reciprocidade. Lévi-Strauss reconhece, portanto, a reciprocidade como estrutura elementar, pelo menos do parentesco, mas para submetê-la a uma estrutura generalizada da troca, inclusive sob suas formas simbólicas.

No mesmo espírito, Alvin Gouldner em The norm of reciprocity (1960) analisa a reciprocidade como norma moral. Trata-se, para ele, de uma norma moral generalizada e universal essencial à manutenção de estruturas sociais e de sistemas sociais estáveis. Identificou formas de reciprocidade assimétricas - que ele qualificou como heteromorfas - assim como a variação das formas de reciprocidade segundo os estatutos dos indivíduos. Mas ele não chegou a examinar quais são as estruturas de base constituídas pelas práticas de reciprocidade (em termos de aliança, de parentesco ou de prestações econômicas), suas condições e seus efeitos, tarefa que ele evocou como o dever do sociólogo (GOULDNER, 1960, p.163).

A primeira parte do texto percorre a mobilização da reciprocidade nos três enfoques. A segunda parte ilustra a sua aplicação ao lugar da reciprocidade no manejo de recursos e territórios comuns. A terceira examina um aporte complementar da teoria da reciprocidade ao enfoque da economia solidária herdado de Polanyi.

\section{Três enfoques mobilizando a reciprocidade}

\section{A reciprocidade na governança dos bens comuns}

Em 1990, no livro Governing the Commons (1990), Ostrom mostra, com a análise de casos empíricos de manejo de recursos naturais em propriedade comum, que o funcionamento da ação coletiva não segue as hipóteses habituais na economia clássica. Os atores, em situação real, fazem opções melhores em termos de ganhos coletivos que aqueles ligados às predições das teorias da escolha racional (OSTROM, 1998). Essa situação explica-se, em parte, pela importância do faceto face ou do interconhecimento entre os atores que leva a um engajamento mútuo. Por outra parte, 
depende da capacidade de inovação dos atores que lhes permite, fazendo evoluir as regras, aprender juntos, reduzir as assimetrias e aumentar os ganhos coletivos (OSTROM, 1990).

Para Ostrom (1998, p. 10), não há cooperação sem reciprocidade, ou seja, sem retorno ou sem compartilhamento por parte dos usuários. Os indivíduos se esforçam em identificar os outros atores envolvidos e os consideram como possíveis cooperadores. Cooperam, a priori, com aqueles que manifestam tal intenção e recusa-se a cooperar se não houver reciprocidade. Ostrom considera a reciprocidade como uma norma social universal no sentido de Gouldner (1960) e a define como a capacidade e a vontade de cooperar.

Para ela é a confiança mútua que explica a reciprocidade (OSTROM, 2003, p.8). A confiança é definida como um nível específico de probabilidade atribuído por um agente a outro, para a realização de uma ação determinada. Explica a permanência da reciprocidade pela existência da confiança ou pelo temor no cumprimento da sanção (OSTROM, 2005). A reputação constitui uma dessas informações, motivando a confiança no outro e, para tanto, a reciprocidade na cooperação (OSTROM, 1998, p. 12). Mas esses valores éticos (confiança, reputação, respeito...) permanecem submetidos aos interesses dos usuários.

A densidade das redes de agentes cooperadores (strong reciprocators) e a probabilidade deles interagirem são dadas como uma condição da expressão da norma de reciprocidade. Ostrom propõe adaptar as políticas em função da proporção de indivíduos “reciprocitários" e egoístas. Se os "reciprocitários" são minoritários numa sociedade, seu impacto depende da densidade das suas interações (OSTROM, 2005).

Para resumir, Ostrom reúne numerosas evidências de dispositivos de cooperação e de reciprocidade que contradizem as teorias econômicas da ação racional. Os indivíduos obtêm resultados melhores que racionais construindo as condições para que a reciprocidade, confiança e reputação contribuam para superar ou reduzir as tentações de interesses egoístas.

A formalização ou a institucionalização das organizações de usuários ou das coletividades territoriais pode assim se tornar necessária para legitimar, num contexto novo, práticas indígenas ou camponesas de reciprocidade ou normas sociais ancestrais como a ajuda mútua ou o manejo compartilhado de recursos comuns. Segundo Ostrom, é o papel dos tomadores de decisão política de cuidar do reconhecimento dessas práticas, das suas regras e dos seus parceiros. 


\section{A reciprocidade na economia solidária}

A economia solidária pode ser definida como uma economia social não fundada unicamente pela concorrência para o lucro individual. A economia solidária é definida pelo governo brasileiro (SENAES, 2005) como “o conjunto das atividades econômicas de - produção, distribuição, consumo, crédito e poupança - organizadas pelos trabalhadores de maneira solidária, em forma coletiva ou autogestão".

Qualquer que seja a sua definição, os enfoques da economia solidária mobilizam a reciprocidade e, geralmente, em referência aos escritos de Karl Polanyi (1944, 1957, 1975).

\section{A contribuição de Karl Polanyi para a reciprocidade no campo da economia}

Karl Polanyi identificou a reciprocidade e a redistribuição como categorias econômicas específicas e diferentes da troca. Ele propôs uma tipologia dos sistemas econômicos considerando diferentes modos de institucionalização do processo econômico na sociedade.

Ele identificou três formas de integração social: a reciprocidade é definida como os movimentos entre pontos de correlação de grupos sociais simétricos; a redistribuição correspondendo "aos movimentos de apropriação em direção de um centro e, em seguida, deste em direção ao exterior"; e a troca, assimilada "aos movimentos de vai-e-vem tais como a passagem de 'uma mão para outra' dos objetos em um sistema mercantil” (POLANYI, 1975, p. 245).

Cada um desses diferentes modelos de integração social supõe suportes institucionais específicos e eles podem se encostar um no outro de maneira articulada: a reciprocidade supõe uma estrutura de grupos de parentesco "simetricamente ordenados". A redistribuição se apoia na existência de um centro de poder dentro do grupo. A troca como modo de integração social apoia-se na existência de um sistema de mercado concorrencial, criador de preço. Polanyi agregou em 1975 a categoria da economia doméstica (livelihood, a subsistência ou o fato de produzir para viver) expressão de base e de realização de uma economia substantiva que seria regulada pelo compartilhamento e a redistribuição (POLANYI, 1997). ${ }^{3}$

Para Polanyi, essas três formas de integração social não são nem lineares nem exclusivas e não correspondem a estágios de desenvolvimento: "Nenhuma sucessão no tempo é subentendida"

\footnotetext{
${ }^{3}$ In the same manner in which either reciprocity, redistribution, or house holding may occur in a society without being prevalent in it, the principle of barter also may take a subordinate place in a society in which other principles are in the ascendant. (POLANYI, 1944, p.59)
} 
(idem, p. 249). Elas coexistem em quase todos os sistemas econômicos, embora uma dentre elas possa ser predominante em uma determinada sociedade, como a troca mercantil desde o século XIX no mundo ocidental. Polanyi explica:

Como forma de integração, a reciprocidade ganha muito em eficiência pelo fato de que ela pode utilizar a redistribuição, assim como a troca, como métodos subordinados. Pode-se chegar à reciprocidade compartindo o peso do trabalho segundo regras precisas e redistribuição, por exemplo, no caso dos turnos; nas economias não mercantis, essas duas formas de integração - reciprocidade e redistribuição - praticam-se geralmente juntas (POLANYI, 1975, p.247; tradução nossa).

\section{Economia solidária e reciprocidade no século XXI}

Castel (2003) identifica dois enfoques da análise teórica da economia solidária. De um lado, o enfoque mais sociológico reconhece a pluralidade das formas da economia. Eme e Laville (1996) identifica a economia de troca do mercado capitalista (ou economia mercantil), a economia pública ligada à redistribuição de recursos pelo Estado e a economia não mercantil assimilada ao princípio de reciprocidade. Por outra parte, a perspectiva mais econômica diferencia os projetos e valores dos sujeitos para empreender atividades econômicas. Existiriam três motivos: o enriquecimento pessoal via a maximização do lucro, motivo principal das atividades capitalistas; o compartilhamento via redistribuição praticada pelo Estado (serviços públicos) ou pelas atividades de proteção dos bens e das pessoas (seguro das sociedades mutualistas e cooperativas); a solidariedade realizada pela reciprocidade, motivo que funda as atividades cooperativas e associativas.

Assim, diversas análises da economia solidária (LAVILLE, SERVET, CATTANI), conduzidas a partir de enfoques diferentes, mobilizam três elementos essenciais da obra de Polanyi: a) a concepção substantiva da economia em oposição a sua definição formalista ${ }^{4}$; b) a existência de uma pluralidade de formas econômicas; c) a inserção das transações econômicas (solidárias) no social e no político (o espaço público segundo Laville). As diversas teorias da economia solidária colocam bem a questão de uma tensão entre o sistema de troca mercantil, o princípio de reciprocidade e o sistema de redistribuição.

\footnotetext{
${ }^{4}$ Processus institutionnalisé d'interaction entre l'homme et la nature qui permet un approvisionnement régulier en ressources matérielles pour la satisfaction de ses besoins (POLANYI, 1957).
} 


\section{A teoria da reciprocidade de Temple e Chabal}

O primeiro elemento próprio à teoria da reciprocidade envolve a definição do conceito do ponto de vista socioantropológico. O princípio de reciprocidade não se limita a uma relação de dádiva/contradádiva entre pares ou grupos sociais simétricos. O reducionismo dessa definição que por muito tempo prevaleceu e ainda prevalece às vezes na antropologia conduz, de fato, a uma confusão entre troca simétrica e reciprocidade. Esse impasse persiste enquanto a reciprocidade for interpretada com a lógica binária que convém à troca. A troca, explica Chabal (1998), pode se reduzir, no limite, a uma permuta de objetos. Temple e Chabal (1995) propõem recorrer à lógica ternária de Lupasco (1951), a qual faz aparecer um Terceiro incluído na relação de reciprocidade. Permite, assim, interpretá-lo ao mesmo tempo como o "resultado e o ser" dessa relação e dar conta dela como da estrutura originária da intersubjetividade, irredutível à troca de bens ou de serviços que libera do elo social ou da dívida.

Do ponto de vista econômico, a reciprocidade constitui, portanto, não somente uma categoria econômica diferente da troca mercantil como havia identificado Polanyi (1944, 1957), mas um princípio econômico oposto ao da troca ou mesmo antagônico da troca.

O segundo elemento da teoria, e que participa do seu caráter universal, é que $a$ reciprocidade pode recobrir várias formas. De forma geral, a antropologia e a etnologia consagraram sob essa terminologia apenas a reciprocidade das dádivas: oferendas, partilhas, prestações totais, potlatch que constituem o que Temple e Chabal (1995) designam pela forma positiva da reciprocidade. Mas existe, igualmente, uma forma de reciprocidade negativa, a dos ciclos de vingança. Diferentemente da troca cujo desenvolvimento ou extensão é associado à lógica da concorrência e do acúmulo pelo lucro, a lógica da vingança está ligada a uma dialética da honra como a da dádiva está ligada a uma dialética do prestígio. Contudo, a sede de prestígio (fonte de autoridade e, portanto, de poder, nas sociedades de reciprocidade) motiva o crescimento da dádiva "mais eu dou, mais eu sou". Entre as expressões extremas das formas negativas e positivas da reciprocidade, as sociedades estabeleceram, então, diversas formas intermediárias. Trata-se, em particular, de controlar o crescimento da dádiva: a ostentação, o potlatch ou a dádiva agonística que destruam e submetam o outro mediante o prestígio.

Em terceiro lugar, as relações de reciprocidade podem ser analisadas em termos de estruturas, no sentido antropológico do termo. Assim, elas podem ser declinadas segundo algumas estruturas elementares (TEMPLE, 1998). As relações de reciprocidade estruturadas sob uma forma 
simétrica são aquelas que geram valores afetivos e éticos como o havia identificado Aristóteles no livro Ética a Nicômaco (1994). A relação de reciprocidade em uma estrutura bilateral simétrica gera um sentimento de amizade; a estrutura de divisão simétrica dos bens dentro de um grupo gera a justiça. Assim, outros tipos de relação organizados em outras estruturas podem produzir outros valores específicos. Esse elemento constitui, sem dúvida, a parte mais complexa da teoria da reciprocidade proposta por Temple e Chabal (1995). É o aspecto mais difícil de validar, visto que ele envolve não somente a produção de valores materiais ou instrumentais, mas também a produção de sentimentos e de valores humanos. É também o elemento mais original e interessante da teoria, aquele que oferece a possibilidade de análises e de propostas alternativas em matéria de economia.

$\mathrm{O}$ quarto elemento da teoria remete aos diferentes níveis do princípio de reciprocidade e aos modos que lhe são específicos. Existem três planos ou níveis de reciprocidade: o real, o simbólico (a linguagem) e o imaginário (as representações).

Assim, existem várias estruturas elementares nas quais as relações de reciprocidade recorrentes geram sentimentos diferentes e, portanto, valores diferentes. Existem, igualmente, várias formas de reciprocidade que lhe conferem imaginários diferentes. O sentimento do ser originário pode ser capturado no imaginário do prestígio ou no da vingança, dando lugar a formas de reciprocidade positivas, negativas e simétricas. Estruturas, níveis, formas se articulam para formar sistemas de reciprocidade.

\section{Aplicação às dinâmicas de manejo de recursos e de territórios comuns}

Como considerar as estruturas elementares de reciprocidade? São construções teóricas, recursos classificatórios para permitir a análise. Segundo Lévi-Strauss (1949), a noção de estrutura designa as diversas maneiras pelas quais o espírito humano constrói valores e sistemas de valores. Nos dispositivos coletivos assegurando o acesso, a produção ou o manejo de recursos comuns, fica impossível dissociar a satisfação das necessidades econômicas da importância (quando não da prioridade) dada ao laço social ou à relação humana de solidariedade. Quando tais formas de relações são recorrentes e reguladas socialmente, elas se institucionalizam, dando lugar a figuras que podemos analisar como estruturas de reciprocidade (TEMPLE, 1998).

As relações mobilizadas nessas estruturas de reciprocidade geram valores materiais e valores instrumentais imateriais, mas produzem também sentimentos, dando lugar a valores afetivos (amizade, proximidade etc.) e a valores éticos como a confiança ou a responsabilidade. 
A distinção de estruturas elementares de reciprocidade, gerando sentimentos de si ou sentimentos compartilhados, dando lugar àprodução de valores éticos, constitui o principal aporte inovador e diferenciado da teoria da reciprocidade. Formulado assim seria apenas um postulado normativo. A validação científica dessa proposta teórica passa por estudos empíricos. Para tanto vou ilustrar aqui a minha proposta, não tanto na base das minhas pesquisas, mas, principalmente, a partir daquelas de autores brasileiros trabalhando no Brasil ou na América Latina.

\section{A produção de valores nas estruturas de reciprocidade}

De acordo com Temple (1998), pode-se classificar as estruturas elementares em dois grupos: reciprocidade binária e reciprocidade ternária, e o grupo da reciprocidade binária em dois outros: o faceto face (cara a cara) e o compartilhamento.

A organização local da produção e a reprodução econômica e social das comunidades e dos territórios rurais do Brasil oferecem exemplos bem atuais das relações de reciprocidade.

A relação de cara a cara é típica da ajuda mútua, do mutirão entre duas famílias de agricultores (CALDEIRA, 1957).

Oliveira e Duque (2004) e Duque et. al, (2004) identificam essa relação entre famílias do semiárido paraibano que praticam o mutirão para a construção de cisternas e no marco de fundos rotativos.

[...] podemos concluir que os laços sociais de reciprocidade e confiança, que constituem a base do processo de sociabilidade camponesa podem ser tanto horizontais - e, nesse caso, reforçam a solidariedade com potencial de organização e conquista da autonomia - quanto verticais - dando origem, ou reforçando, uma cultura da subalternidade que impede a autonomia, favorecendo o clientelismo. (DUQUE et al., 2004, p. 125)

Aveline (2015) identifica a produção de amizade mediante a ajuda mútua entre duas famílias de Mambaí - GO para a comercialização dos seus produtos (carona solidária, comercialização cooperada, venda portaaporta). Ele observa que "dois agricultores se juntaram para produzir e comercializar: Valdecir, que possui 'contratos sem assinar' (venda direta fundada na relação de confiança), e a prática da ajuda mútua no Assentamento São José para transportar e vender”.

Esse sentimento de amizade pode se prolongar por alianças mais duráveis como o compadrio ou o casamento de filhos (MAYER, 2002). 
A estrutura de compartilhamento está sendo verificada em vários casos de gestão de bens em propriedade comum: recursos naturais (terra, pastagens, água, reserva florestal extrativa) ou equipamentos coletivos (casa de farinha, sistema ou rede de irrigação), assentamentos de reforma agrária (LAZZARETTI, 2006) ou perímetros irrigados (MARINOZZI, 2000).

A tese recente de Pugen (2015) no Rio Grande do Sul evidencia a produção de sentimentos e de valores éticos a partir do manejo compartilhado de um território de turismo rural

A alegria com que doavam isto em cada visita era visível e pode-se interpretá-la como um momento de criação de um vínculo, pois os agricultores se sentiam orgulhosos e valorizados por participarem também de um estudo acadêmico. Inicialmente, o que poderia ser uma dádiva interessada (eles forneceriam informações a mim e eu poderia oferecer auxilio técnico a eles) se mostrou dádiva geradora de valor ético: respeito e amizade (PUGEN, 2015, 82).

Vários exemplos de citações da tese indicam a produção de sentimentos e de valores: Parece um membro da família; Não adianta simplesmente fazer por fazer, nós temos que deixar alguma coisa para os turistas; Na questão financeira ajuda, mas eu me sinto bem porque a gente tem mais uma autoestima, né? Se sente valorizado, as pessoas conversando, parece assim que a gente se sente respeitado pelos outros; Dai estas pessoas de fora vinham e começavam a adquirir os produtos, mas a gente nunca explora eles [os turistas]; Eu sempre pensei assim: em tirar o lucro que não me desse prejuízo, mas que eles pudessem levar e ficar bom pra eles também; Se fosse pelo dinheiro nós não estaríamos mais participando.

As estruturas de reciprocidade ternária envolvem pelo menos três partes. A reciprocidade ternaria pode ser unilateral. É o caso, por exemplo, da transmissão entre gerações: transmissão de saberes (educação, iniciação, aprendizagem).

$\mathrm{Na}$ Universidade Camponesa no Cariri - PB, as avaliações em termos de aquisição de competências e de aprendizagem social ou coletiva expressam de maneira clara a existência de uma produção associada de valores éticos e simbólicos (respeito, confiança, dignidade), mas também afetivos (amizade, solidariedade) junto com os valores materiais ou instrumentais (COUDEL e SABOURIN, 2005; COUDEL et al., 2009).

Essa geração de confiança foi promovida e construída porque a metodologia da estrutura de formação entre pares permitiu um tratamento aberto, de respeito e de humildade, de humano para humano, entre os formandos e formadores. Não se trata apenas de produzir ou de transmitir conhecimentos, mas de criar as condições coletivas e institucionais da aprendizagem, o que supõe começar por devolver ou dar dignidade e palavra aos camponeses em capacitação. Trata-se, portanto, também, de dar conhecimentos, de compartilhar opiniões e tomadas de consciência 
mútuas e coletivas. Por fim, trata-se de compartilhar práticas: práticas pedagógicas, visitas de observação, viagens de estudo e, sobretudo, trabalhos manuais de artesanato e de artes.

Os formandos explicam o sucesso ou a eficiência das aprendizagens pela importância:

- do respeito do outro (formando ou formador), da capacidade de escuta que tem gerado essa confiança no seio do grupo;

- das relações de intercâmbio mútuo (recíproco) com outros profissionais ou atores sociotécnicos (agricultores, artesões, poetas, artistas);

- da prática coletiva de trabalhos manuais nas aulas e oficinas de artes plásticas, incluindo a aprendizagem por todos os professores, o que tem criado relações horizontais interpares entre formandos e entre formadores e formandos, além dos diferentes estados sociais ou profissionais.

Finalmente, os formandos destacaram a produção de várias configurações de produção de valores éticos: a) respeito, reconhecimento e amizade são produzidos pela situação de "cara a cara" ou reciprocidade bilateral simétrica; b) a confiança coletiva é produzida pela estrutura de compartilhamento no sentido de compartilhar algo no seio do grupo: participação compreendida, repartição e solidariedade; c) o sentimento de justiça na aprendizagem e na tomada de consciência é produzido pela equidistância entre a necessidade do saber (a sua aplicação, para si e para os outros) e a fonte do saber (personificada pelo formador), corresponde à estrutura de reciprocidade ternária bilateral.

Segundo o mesmo princípio, mas no caso de incubadoras de empreendimentos solidários no Distrito Federal, Rosana Kirsch (2007) mostra como para conseguir motivar os adultos, os pedagogos têm construído relações pedagógicas de reciprocidade simétrica, valorizando uma aprendizagem mútua e equilibrada entre formadores e formandos. Assim, "tanto do ponto de vista simbólico como real (os aspectos materiais e imateriais dos saberes compartilhados), uma pedagogia de reciprocidade educativa favorece a constituição de uma relação de reciprocidade mais simétrica entre a incubadora e o empreendimento solidário, gerando serviços materiais, conhecimentos, mas também valores afetivos: amizade, respeito, autoestima, e éticos: dignidade, responsabilidade, confiança (KIRSCH, 2007; KIRSCK e SABOURIN, 2007).

Radmosky e Schneider (2007, p. 272) evocam também a importância dos próximos para compartir informações no caso do mercado das frutas no Rio Grande do Sul: O que fazíamos anteriormente era buscar familiares, parentes, amigos, conhecidos [para trabalhar]. Hoje, o que a gente faz para conseguir informações. Nós buscamos familiares, parentes, amigos e conhecidos.

No município de Unaí - MG, Lenne (2006) acompanhou a confrontação e a partilha de conhecimentos entre pesquisadores e agricultores no marco de dispositivos de inovação 
participativa em torno de sistemas de plantio direto de grãos nos assentamentos de reforma agrária. Ela analisa, de um lado, os conhecimentos produzidos ou partilhados em termos de objeto, e de outro lado, os valores humanos éticos ou afetivos associados às dinâmicas sociais dos conhecimentos. De fato, os agricultores, em grande parte, mas também os pesquisadores, não conseguem separar a produção, a aquisição ou a transmissão de saberes ou de um saber-fazer, das relações humanas e sociais (inclusive as relações institucionais e de poder) dentro das quais acontecem os processos de diálogo ou de experimentação (LENNE, 2006).

São esses valores, geralmente não identificados e reconhecidos pelos usuários, que permitem manter as regras de compartilhamento ou de ajuda mútua entre os beneficiários. Além de produtos, tornam-se, assim, motores da reprodução das relações de reciprocidade, pois tais relações permitem, pelo menos, reproduzir as regras ou os ciclos desses dispositivos de ajuda mútua, de transmissão de patrimônio, mas como já vimos nos exemplos citados, de manejo compartilhado de diversos tipos de recursos.

\section{As instituições na gestão compartilhada de recursos}

Uma análise do papel e do lugar dos valores éticos na teoria da governança dos comuns (OSTROM, 1990) e na teoria da reciprocidade (TEMPLE, 2003) permite entender a suas diferenças em torno da mobilização da reciprocidade.

Ostrom observa que na estrutura de compartilhamento, o fazer juntos, o fato de depender de um mesmo recurso ou território limitado cria um sentimento de pertencimento ao grupo e estabelece relações de confiança entre os indivíduos (OSTROM, 2003, p. 18). No entanto, para a teoria da reciprocidade, a confiança, a reputação (o prestígio) são valores éticos gerados pelas relações simétricas, em função de um projeto de sociedade (comunitário, humano) fundado no interesse dos homens em viver juntos, antes que fazer produzir a natureza juntos. Para Ostrom, a relação com a natureza determina as relações dos homens entre eles. $\mathrm{O}$ fato que a terra alimente os homens implique que eles possam se apropriar de forma privada ou manejá-la coletivamente de acordo com a natureza dos recursos. Seriam, assim, os atributos dos "bens" que passariam a determinar o comportamento dos humanos. $\mathrm{Na}$ análise da teoria da reciprocidade é o contrário: são as relações entre os homens que podem permitir definir a propriedade como responsabilidade social, associando o bem (o recurso, o território) apropriado a uma função social. É o caso da função social da terra na constituição brasileira como base da regra de repartição e de reforma agrária. Dito de 
outra maneira, o rio rega a terra e a terra produz alimentos. Mas a relação dos homens com a natureza é ordenada pela relação entre os homens: o rio rega as terras de todos, a terra produz alimentos para todos.

Até os anos 2000, Ostrom (1998) considerou que as normas que ela chama "atributos das comunidades de usuários" (a saber: a confiança, a reputação, a reciprocidade, o sentimento de pertencimento e a percepção comum do recurso) eram historicamente e socialmente construídas, o que condiz com a teoria da reciprocidade. Mas Ostrom não identificou a origem dessas normas e, em particular, das relações de reciprocidade que ela evidencia e valida experimentalmente pela teoria dos jogos. Portanto, foi buscar uma explicação do lado da sociobiologia (OSTROM, 2003, p.9), inclusive por meio da hipótese arriscada de um altruísmo biológico (KURZBAN, 2005).

Resumindo, Ostrom considera a reciprocidade como uma norma moral internalizada e um princípio de troca social, caracterizada pela vontade de cooperar. Ela identifica e descreve certas relações de reciprocidade estruturadas e recorrentes. Dá uma importância especial à reciprocidade até o ponto de fazer depender as políticas públicas da proporção de atores "reciprocitários" (OSTROM, 2003, p.18). Mas fica prisioneira dos limites do quadro econômico utilitarista no qual analisa a gestão comunitária e a sua regulação por uma minoria e indivíduos altruístas e "reciprocitários". Ostrom não questiona o uso da produção gerada pela gestão e propriedade comum, quer dizer, a sua integração ao mercado da troca capitalista.

Para explicar a reciprocidade, ela invoca a primazia da confiança, quando para a teoria da reciprocidade são as relações de reciprocidade simétrica nas estruturas de compartilhamento (de recursos comuns) que produzem a confiança entre os membros do grupo. De fato, é também o que mostram as repetições modelizadas dos jogos que mobilizam comportamentos de confiança e de reciprocidade, a partir do momento que se introduz uma variável de conhecimento do comportamento do outro forjado na experiência. Tanto Ostrom como a teoria da reciprocidade reconhecem que o manejo de recursos comuns funciona melhor em grupos de tamanho humano ou em sociedades de proximidade fundadas na construção e no respeito de regras comuns. De fato, as relações de reciprocidade funcionam bem melhor se cada um sabe que os seus interlocutores se situam também num quadro de reciprocidade.

Por suposto, o reconhecimento institucional ou público dos dispositivos de manejo compartilhado de recursos comuns fundados em relações de reciprocidade pode garantir ou facilitar a perenidade dessas estruturas. Mas o mais importante é garantir também o entendimento dos mecanismos de reprodução dos valores humanos que contribuem para gerar a confiança, a reputação, o respeito mútuo, a responsabilidade e a justiça (SABOURIN, 2010). 


\section{Economia solidária: hibridação, contradição e sistemas mistos}

\section{As articulações entre troca, reciprocidade e redistribuição}

Eme \& Laville (1996), Laville (2000, 2003), Cattani (2003) e França Filho (2006) propõem fundar a economia solidária no princípio de hibridação entre as três formas da economia plural herdadas de Polanyi: reciprocidade, redistribuição e troca. No entanto, a dificuldade dessa proposta vem da questão da articulação entre essas três formas econômicas. Para Castel (2003), esse enfoque é problemático, pois uma empresa capitalista pode também se beneficiar da hibridação dos recursos: vende a sua produção no mercado capitalista (troca mercantil) e pode obter subsídios públicos ou exoneração fiscal (redistribuição pública) e está inserida em redes empresariais ou interpessoais reguladas pela reciprocidade. Pode também mobilizar a reciprocidade ao título da responsabilidade social ou efetuar dádivas para fundações caritativas para conseguir exoneração de impostos, sem ter nada de solidário.

Segundo Temple (2003), Castel (2003) e Gardin (2006, p. 41), dois desses princípios econômicos são antagônicos: a maximização do lucro por meio da troca e a reciprocidade. O lucro monopolizado pelo patrão pró́be seu uso solidário. O princípio de redistribuição pode ser compatível tanto com o princípio de troca ou com o princípio de reciprocidade.

Para superar esse limite do uso da "hibridação", proponho a noção de "sistema misto", que pode se aplicar às situações nas quais coabitam relações de reciprocidade e de troca, o que corresponde à maioria das nossas sociedades contemporâneas. Essa coabitação pode se dar de maneira paralela, separada ou mediante uma tensão por conta do antagonismo entre sistema de troca e sistema de reciprocidade. Pode também acontecer de maneira complementar quando existe uma interface de sistema permitindo articular práticas de reciprocidadee práticas de troca mercantil.

Os sistemas mistos podem, assim, ser declinados em função das modalidades de articulação entre as lógicas de troca e de reciprocidade:

a) a justaposição de mundos paralelos: as práticas de troca e de reciprocidade coexistem sem se misturar, podendo até ignorar-se;

b) a complementariedade reversível: as práticas de troca e de reciprocidade sendo reconhecidas como de natureza diferente; os atores as articulam de maneira complementar na base de uma interface; corresponde à situação da hibridação proposta pela teoria da economia solidária; 
c) a contradição entre lógicas de reciprocidade e lógicas de troca com dois tipos de consequência: paralisia mútua dos dois sistemas ou dominação de um pelo outro. ${ }^{5}$

Observei, sobretudo, contradições levando a uma justaposição ou uma oposição das esferas da troca e da reciprocidade. Essa contradição é inerente à proposta da economia solidária. Trata-se, portanto, de reduzir o antagonismo entre um funcionamento regulado pela reciprocidade e o compartilhamento no seio do empreendimento solidário e, fora dele, por um mercado de troca fundado na concorrência pelo lucro. Para que exista a complementariedade entre os dois sistemas (e a sua "articulação" mais que sua "hibridação") necessita-se uma interface de sistema para resolver a contradição.

A noção de sistemas mistos é operacional para dar conta de uma pluralidade de lógicas econômicas. A noção de hibridação (LAVILLE, 2000), sem ser errada, é parcial. Ela considera apenas a hipótese da complementariedade entre os dois sistemas, como se esta fosse natural.

Mas os fatos mostram também situações de desenvolvimento paralelo ou de justaposição no caso dos mercados andinos (YAMPARA et al., 2007) ou Kanak (SABOURIN e TYUIENON, 2007), e de antagonismos levando a várias formas de bloqueio. Concretamente, a maioria das dificuldades dos empreendimentos solidários, das comunidades rurais e das suas organizações se situa na interface entre a esfera da troca e aquela da reciprocidade. Para Servet (2007, p. 264, tradução nossa)

[...] mercado de troca e reciprocidade são, deste ponto de vista, antinômicos.A preocupação com o outro da reciprocidade se opõe ao interesse para si do princípio da troca mercantil. Devemos notar que Polanyi parece guardar da reciprocidade apenas suas dimensões positivas. Seria errado de confundir reciprocidade e simples afeto supostamente generoso, uma dádiva que seria gratuita e não interessada.

\section{Sistemas mistos nos mercados e nas redes}

Em matéria de comercialização dos produtos agrícolas, os agricultores e as suas organizações têm implementado vários tipos de interface permitindo uma coabitação, uma articulação entre práticas de reciprocidade e práticas de troca.

\footnotetext{
${ }^{5}$ Não se trata de entra em juízo de valor, mas de explicitar as diferenças de natureza entre os dois sistemas e as configurações intermediárias que podem existir entre a polaridade da troca e aquela da reciprocidade. São representações teóricas e ferramentas de análise: não vamos perguntar diretamente a um agricultor ou a um comerciante "de que estrutura elementar de reciprocidade eles participam"?
} 
A primeira interface é aquela da venda direta que permite o encontro entre produtor e consumidor, na unidade de produção, ou em mercados de proximidade, mercado dos produtores ou de feiras. Existe uma relação de troca mercantil, mas o contato direto entre produtor e comprador permite uma relação de reciprocidade binária (cara a cara) que gera também valores afetivos: sentimento de amizade, de reconhecimento ou valores éticos de fidelidade e de respeito.

E também o caso dos circuitos curtos controlados socialmente por grupos de produtores ou por cooperativas de consumidores. ${ }^{6}$

O contato direto dá lugar a relações humanas: conversas e explicações sobre o trabalho, os produtos, os processos, receitas. Elas motivam, geralmente, sentimentos de amizade e valores de confiança e fidelidade entre produtores e consumidores.

Quando a relação direta não é possível, existe a possibilidade de uma intermediação qualificada e interpessoal, a corretagem. O corretor permite uma relação de reciprocidade ternária por meio da informação sobre a qualidade do produto e do interconhecimento entre produtor e comprador. Essa relação produz confiança, responsabilidade e a reputação (do produtor e do corretor), que é fonte de prestígio.

Segundo Servet (2007, p. 263), de acordo com Polanyi (1957, p. 48-49) diferentemente da troca mercantil, "a reciprocidade supõe que os parceiros estejam numa relação de complementariedade ou de interdependência voluntária”. Para Servet (2007, p. 264)

[...] é possível designar essas relações acontecendo no mercado de proximidade como laços de clientela. Nessa lógica, diferente da troca, observam-se em particular práticas de discriminação dos compradores com a vontade de fidelizar o cliente, perpetuando a relação. Não se trata aqui de firmar um contrato que uniformize os contratantes como equivalentes numa relação que se limitaria a essa única operação.

Exemplos desses processos nos são dados por Radomsky e Schneider (2007, p. 269) no caso dos produtores fruteiros de Veranópolis (RS), observando que os laços de amizade e os vínculos são centrais para o acesso à rede, e funcionam como suporte para os novos negócios.

As relações em rede e as formas de reciprocidade não são apenas importantes para entrar no mercado de trabalho via indicação. Estas relações constituem maneiras de instituir os empreendimentos. [...] Portanto, as relações de reciprocidade, que redundam em confiança, são importantes, pois um indivíduo sozinho talvez não se lançasse em novos empreendimentos - cujo risco é desperdiçar os esforços. A

\footnotetext{
${ }^{6}$ Ou pelos dois juntos, como no caso na região de Porto Alegre - RS entre cooperativas do MST e cooperativas de consumidores (EID, 2006).
} 
conclusão mais importante sobre este aspecto é que as relações de proximidade são fundamentais quando os capitais econômicos são escassos (idem, p. 268).

Este é o efeito multiplicador na economia local e, via condutas de reciprocidade, a rede conecta pessoas ao mercado de trabalho (que na realidade é uma rede de laços sociais, inclusive de trabalho) e empresas a um sistema local. (p. 273).

\section{Os limites do enfoque de Polanyi para a economia solidária}

De acordo com Polanyi (1944), o que distingue reciprocidade e redistribuição da troca mercantil depende precisamente dos valores sociais e dos códigos morais nos quais se inserem as transações. Por isso, fala de uma economia inserida (embedded) num sistema de valores que se impõeàs leis da oferta e da demanda. Esses valores são mobilizados pela iniciativa de cada um no caso da reciprocidade ou dependem de um mesmo centro de referência para todos no caso da redistribuição (o rei, a Igreja, o Estado). Bastaria liberar as transações de suas obrigações morais ou sociais para que se tornem "trocas puras". Polanyi analisa assim a emergência da livre troca (do liberalismo que ele denuncia) da reciprocidade, a partir da separação das funções sociais e econômicas anteriormente confundidas. Mesmo se Polanyi reconhece a existência de sistemas econômicos que não obedecem apenas ao princípio do enriquecimento individual, ele limita a perspectiva da sua descoberta, considerando os sistemas de reciprocidade e redistribuição como formas pré-capitalistas. Mas o principal limite da teoria de Polanyi é o fato de não explicar como são produzidos esses valores nos quais seriam inseridas as prestações econômicas.

Como surgem esses valores evocados individualmente ou pelo rei? Se não se reconhece a sua matriz na reciprocidade, então devem ter uma origem exterior às relações de reciprocidade: os deuses e os espíritos da natureza para uns, a origem divina do rei para outros, ou ainda a ideia de Lévi-Strauss (1949) da cultura emergendo das formas mais organizadas e estruturadas da vida.

Segundo a teoria da reciprocidade de Temple (1997), esses valores humanos não são dados, devem ser constituídos. São precisamente gerados e reproduzidos pela institucionalização dos ciclos de reciprocidade e de redistribuição em estruturas, não apenas sociais, mas, também, econômicas. Polanyi não chegou a reconhecer na reciprocidade e na redistribuição as estruturas matrizes dos valores simbólicos e éticos. Assim, ele tem, como Lévi-Strauss, uma dificuldade em distinguir a reciprocidade de uma troca mútua igualitária ou simétrica, porque separando a reciprocidade dos valores que ela produz, apenas permanece uma prestação que se torna difícil de diferenciar de uma troca recíproca. 
Para Temple (1997) e Gardin (2006), as estruturas de reciprocidade geram valores materiais de uso, mas também valores humanos ou éticos: amizade entre próximos, confiança entre usuários de um mesmo recurso comum, responsabilidade entre gerações e perante os recursos naturais ou ainda justiça e equidade a partir das modalidades da redistribuição pública.

Pelo tanto, as capacidades e os projetos dos indivíduos, das suas organizações, comunidades e sociedades, podem variar dialeticamente entre duas tendências opostas, e às vezes complementares: de um lado a produção de valores materiais destinados à troca mercantil para o lucro, e do outro, a produção de valores éticos, associada à produção de valores de uso, destinados ao consumo (a economia doméstica), à redistribuição (ou o compartilhamento) ou à reciprocidade generalizada (o mercado de reciprocidade segundo Temple, 2003).

\section{Considerações finais}

Além das numerosas constatações empíricas comuns às três teorias, existe uma diferença de enfoque e de postulado que torna de fato o diálogo complexo, mesmo se, às vezes, parece que a distância entre essas três propostas não seja tão grande.

Para resumir, o principal aporte da teoria da reciprocidade é oferecer uma explicação quanto à origem dos valores sociais e éticos "reguladores" dos comportamentos socioeconômicos mobilizados tanto pelo enfoque da governança dos comuns como pela abordagem da economia solidária herdada de Polanyi.

Em segundo lugar, a proposta da existência de "sistemas mistos" em tensão dialética permite completar a proposta parcial da hibridação das formas econômicas plurais da economia solidária.

Finalmente, em termos de projeto territorial e de instrumentos de política pública, o terceiro elemento diferenciador é aquele da interface de sistema entre lógicas de troca e lógicas de reciprocidade.

A proposta do desenvolvimento sustentável ou territorial arrisca morrer das suas contradições e da sua falta de operacionalidade. No entanto, existem dispositivos de desenvolvimento territorial baseados em uma negociação entre organizações de produtores, de usuários e serviços públicos do Estado que permitem desenvolver exemplos concretos de interface de sistemas em situações mistas ou até dominadas pela lógica da troca.

Temple (2003) lembra que nesse tipo de situação existe uma antinomia entre as sociedades de reciprocidade e as sociedades ocidentais, que até então só se resolveu mediante o uso da força, e 
que, geralmente, termina sendo historicamente a favor do princípio da troca mercantil e dos ocidentais. Contudo, tudo se complica quando os povos indígenas ou as comunidades pobres querem também ter acesso aos benefícios da modernidade. Essas vantagens são, de fato, criadas no quadro do mercado capitalista e, mesmo se elas são o produto do trabalho humano, o acúmulo do capital constitui igualmente um fator de sua produção. Trata-se, portanto, de pensar a humanidade a partir da tensão entre uma organização econômica própria às comunidades e uma organização econômica do comércio capitalista no seu exterior, cuja confrontação deve ser articulada e negociada.

Ela poderia ser arbitrada pelo Estado? Podemos considerar o Estado nacional como um centro de reciprocidade e de redistribuição? Trata-se, então, de definir uma política contratual entre as comunidades e o Estado.

Um primeiro tipo de interface é aquele dos instrumentos de apoio aos dispositivos locais, assegurando o manejo ou a produção de bens comuns na base de relações de reciprocidade (SABOURIN, 2010). O segundo se refere aos mercados públicos que, assim como a qualificação dos produtos, configurem territorialidades de reciprocidade, protegidas da concorrência capitalista.

É o caso dos instrumentos de regulação de dispositivos coletivos de manejo de terras e de recursos comuns (água, floresta, pastos, biodiversidade): as áreas de pesca artesanal, as colônias de pescadores, as resex, os assentamentos, fundos de pasto, faxinais, bancos de sementes comunitários, reservatórios comuns de água e sistemas coletivos de irrigação, etc. É também o caso de dispositivos coletivos produzindo bens públicos ou comuns localizados (informação, inovação, educação, saberes locais ou acesso aos mercados): mediante os grupos de inovação, os agricultoresexperimentadores, escolas familiares rurais, mercados e feira de proximidade ou associativos, etc. Tais instrumentos oferecem uma alternativa em termos de estratégia de desenvolvimento rural e territorial sustentável. São particularmente adequados para políticas, valorizando a multifuncionalidade da agricultura e dos espaços rurais, os serviços ambientais e os atributos específicos dos territórios. São aquelas iniciativas e aqueles dispositivos locais que a política de desenvolvimento territorial deveria priorizar e apoiar em vez de financiar, sobretudo, tanques de leite, pás retroescavadoras ou patrulhas mecanizadas.

"No entanto, o argumento é que os atores sociais analisados compartilham recursos sociais e simbólicos no território, que são essenciais para gerar efeitos benéficos do ponto de vista social e econômico" (RADOMSKY e SCHNEIDER, 2007, p.278).

A qualificação e a certificação dos produtos agrícolas são outros exemplos de dispositivo coletivo que pode delimitar uma fronteira de sistema ou uma territorialidade de reciprocidade, 
protegendo certos produtores da concorrência da troca capitalista (SABOURIN, 2013). No Agreste da Borborema - PB, Marlene Pra (2015) evidencia a construção social do acesso ao mercado de agricultores familiares mediante as feiras agroecológicas e a construção de uma relação de confiança com os consumidores pobres mediante preços modestos e um sistema participativo de certificação social.

Uma das principais dificuldades das políticas de economia solidária ligada à sua base teórica reside precisamente nessa questão da articulação entre empresa solidária regulada pela reciprocidade (solidariedade e compartilhamento entre os trabalhadores) e o mercado capitalista regulado pela lógica da troca (concorrência para a acumulação privada). De fato, os mercados e as compras públicas, dos municípios ou do Estado, ao exemplo do Programa de Aquisição de Alimentos e do Programa Nacional de Alimentação Escolar correspondem a uma interface determinada por uma política pública específica. Mas, de maneira realística, não pode ser a única alternativa. É necessário construir outras interfaces, ao exemplo da qualificação por selos locais e territoriais associados à certificação participativa (MEDAETS e MEDEIROS, 2004), às feiras dos produtores ou a outras modalidades de mecanismos de conversão (PLOEG, 2008) como a agroecologia. Mas os territórios têm que experimentar outros tipos de interface, por exemplo, mediante novas formas de produção de energia, de reciclagem dos resíduos ou de transporte solidário que possam escapar, pelo menos em parte, do controle das firmas e dos estados ligados ao sistema de troca capitalista.

De fato, a teoria da reciprocidade não nega a existência do princípio da troca do ponto de vista econômico e social, pelo contrário. Não propõe tampouco substituir sistematicamente relações de troca por relações de reciprocidade. Chama para uma dupla leitura da economia e da sociedade. Cada uma dessas lógicas, troca e reciprocidade, pode se valer de vantagens respectivas e, sobretudo, de vantagens adquiridas, das quais algumas sejam, talvez, irreversíveis. Não se trata de negar a importância das relações de troca e de propor uma volta às origens ou de pretender a exclusividade de uma ou outra dessas duas lógicas, mas pelo menos a dupla referência, como propõe Gardin (2006, p. 47-50). Como escreve Temple (1997, p.107)

[...] o reconhecimento científico e político da economia de reciprocidade tem o mérito de delimitar uma articulação ou uma interface de sistema entre sistemas de troca e de reciprocidade. Isto permitiria um debate entre os defensores de uma ou outra lógica para tratar da natureza das organizações, da delegação do poder, das normas e dos princípios de gestão dos bens comuns e públicos, e, de maneira geral, dos valores que devem fundar os projetos de desenvolvimento econômico e social. 
Sem interface, o quiproquó entre a natureza das lógicas de reciprocidade e de troca funciona para o benefício exclusivo da acumulação. Enquanto a economia política não reconhece senão uma só lógica econômica, a do comércio livre e do neoliberalismo, então será mantido o reino do pensamento único, mesmo disfarçado atrás de diversas escolas ou teorias chamadas de não ortodoxas.

\section{Referências}

ARISTOTE. Ethique à Nicomaque, Tricot, Paris:Vrin, 1994.

AVELINE, I. A. A agricultura familiar e a construção social de mercados em assentamentos rurais do município de Mambaí, nordeste de Goiás. Brasília, Universidade de Brasília, CDS. Projeto de qualificação de mestrado, 2015.

BRASIL. Secretaria Nacional de Economia Solidária. Programa Economia Solidária em desenvolvimento. Brasília: Senaes-MTD, 2003.

CALDEIRA, C. Mutirão, formas de ajuda mútua no meio rural. São Paulo: Companhia Editora Nacional, 1957.

CASTEL, O. La dynamique institutionnelle de l'économie populaire solidaire dans les pays du Sud, Chaire de recherche en développement des collectivités. Québec : Université du Québec en Outaouais,2003. (Série Comparaisons internationales, n.4)

CATTANI, A. D. (Org.). A Outra economia. Porto Alegre: Veraz, 2003.

COUDEL, E.; SABOURIN, E. Apprentissage et action collective au Nordeste du Brésil: l’Université Paysanne, Montpellier, Cirad - Inra, Rapport du projet Accolade, 35p., 2005.

COUDEL, E.; SABOURIN, E.; TONNEAU, J.P.Dynamiques et apprentissages d'une première expérience de construction d'une Université Paysanne au Brésil. In: TURCKHEIM, E.; HUBERT, B.; MESSEAN, A. (Coords.) Concevoir et construire la décision: démarches en agriculture, agroalimentaire et espace rural. Versailles, Editions Quae, 360p. Update Sciences \& Technologies, 2009.

DUQUE, G.; SIDERSKY, P.; OLIVEIRA, M. S. L. Fundos rotativos: organização e desenvolvimento local no semi-árido paraibano -Potencial e limites do resgate das tradições de reciprocidade. Revista Raízes, UFCG/PPGS, vol. 23, 17-126, 2004.

EID, F., PIMENTEL, A. E., SEVERINO, M. M.; SANTOS, C. Cadeias produtivas sob controle de famílias cooperadas do MST. Anais do VII Congresso Latino americano de Sociologia Rural ALASRU.Quito, Equador, 20-24/11, 2006.

EME, B.; LAVILLE,J.L. Economie plurielle, économie solidaire.Revue du Mauss, n. 7, 1996. 
FRANÇA FILHO, G. C. de. Políticas públicas de economia solidária no Brasil. In: FRANÇA FILHO G.; LAVILLE, J.; MEDEIROS, A.; MAGNEN, J. P. (Orgs.). Ação pública e economia solidária: uma perspectiva internacional. Porto Alegre: EDUFRGS; Salvador: EDUFBA, 2006.

GAIGER, L. Empreendimentos econômicos solidários. In: CATTANI, A. (Org.). A outra economia. Porto Alegre: Veraz, 2003. p. 135-143.

GAIGER, L. I. G. Apontamentos sobre a natureza do vínculo solidário na vida econômica. XXIX EncontroAnual da ANPOCS, 2005. 23 p.

GARDIN, L. Les initiatives solidaires. La réciprocité face au marché et à 1'Etat. Paris: Eres, 2006. $190 \mathrm{p}$.

GOULDNER, A. W. The Norm of Reciprocity. American Sociological Review, 25-2. p. 161-178, 1960.

HILLENKAMP, I. Économie de marché et économie solidaire: stratégies des petits producteurs boliviens dans une économie dérégulée. Autrepart, 43, 3, p. 177-190, 2007.

KIRSCH, R. Incubação de empreendimentos da economia solidária e as implicações das relações de reciprocidade. Brasília, UnB, Dissertação de mestrado em Sociologia, 260 p., 2007.

KIRSCH, R., SABOURIN, E. Implicações das relações de reciprocidade na incubação de empreendimentos da economia solidária. XIII Congresso Brasileiro de Sociologia, Recife, 2007.

KURZBAN, R. Biological foundations of reciprocity, In: OSTROM, E.; WALKER (Eds.) Trust and reciprocity: interdisciplinary lessons for experimental research.New York: Russell Sage Foundation, 2003. p. 105-127.

LAVILLE, J.L. L'économie solidaire: une perspective internationale. Paris: Desclée de Brouwer, 2000. 343 p.

. Economia solidária, a perspectiva européia. Sociedade e Estado, n. 16, v. 1-2, Brasília, p. 57-99, 2002.

LAZZARETTI, M. A. Ações coletivas nos assentamentos do MST: relações de poder e subjetividade. Campina Grande: Universidade Federal de Campina Grande - Programa de PósGraduação em Sociologia. Tese, 2007.

LENNE, P. Confrontation des connaissances entre agriculteurs et chercheurs dans un dispositif de co-construction de l'innovation: le cas du semis direct à Unaí (MG - Brésil). Master Pro, anthropologie du développement local, IEDES, Paris I Sorbonne, Cirad, 2006.

LÉVI-STRAUSS, C. Les structures élémentaires de la parenté. Mouton: La Haye, [1947], 1967.

. Introduction à l'œuvre de Marcel Mauss. Mauss M. Sociologie et Anthropologie, PUF, Paris, 482 p., [1950], 1989. 
LUPASCO, S. Le principe d'antagonisme et la logique de l'énergie. Paris: Herman, 1951.

MALINOWSKI, B. Les argonautes du Pacifique Occidental. Paris: Payot, 1963.

MARINOZZI, G. Stratégies collectives et dispositifs de commercialisation: l'essor de la fruticulture irriguée à JuazeiroPetrolina. Université de Toulouse, Essor, Thèse de Doctorat en économie, 2000.

MAUSS, M. Essai sur le Don. Sociologie et Antropologie, Paris, PUF, Edition 7, [1950], 1989.

. Euvres. Paris: Ed. de Minuit, 1968-1969.Volume III.

Manuel d'ethnographie. Paris: Payot, 2002.

MAYER, E. The Articulated Peasants: Household Economies in the Andes. Boulder: Westview Press, 2002.390p.

MEDAETS, J. P.; MEDEIROS, J. X.A Ação coletiva no controle da qualidade da produção orgânica familiar: análise comparativa entre a certificação por auditoria externa e a certificação participativa em rede. XLII Congresso da SOBER, 2004.

NUNES, C.G. F. Politiques publiques en faveur de l'économie solidaire au Brésil. Tiers Monde, $\mathrm{n}$. $190: 379-399,2007$.

OLIVEIRA, M. S. L., DUQUE, G. Reciprocidade e sociabilidade no Cariri Paraibano. XXIV Reunião Brasileira de Antropologia, Olinda, 20 p., 2004.

OSTROM, E. A behavioural approach to the rational-choice theory of collective action. American Political Science Review, 92, 1-22, 1998.

. Toward a behavioral theory linking trust, reciprocity and reputation. In: OSTROM, E.; WALKER, J. (Eds.) Trust and reciprocity: interdisciplinary lessons for experimental research.New York: Russell Sage Foundation, 2003. p. 19-78.

. Policies that crowd out reciprocity and collective action. In: GINTIS, H.; BOWLES, S.; $\overline{\mathrm{BOY}} \mathrm{D}, \mathrm{R}$;; FEHR, E. Moral sentiments and material interests: the foundations of cooperation in economic life. Cambridge: MIT Press, 2005. p. 253-275.

PLOEG, J.D.V. The new peasantries: struggles for autonomy and sustainability in an era of empire and globalization.London: Sterling, Earthscan, 2008. 356 p.

POLANYI, K. L'économie en tant que procès institutionnalisé. In: POLANYI, K.; ARENSBERG, C. Les systèmes économiques dans l'Histoire et dans la Théorie. Paris: Larousse, 1975. p. 239260.

. The livelihood of man. In: EI sustento del hombre. Barcelona: Mondadori, 1994.

. The great transformation. Boston: Beacon Press. Référence A grande transformação: as origens da nossa época. Rio de Janeiro: Campus, 1980. 306 p. 
PRA, M. Logiques et stratégies de commercialisation des agriculteurs familiaux de l'Agreste de la Paraíba au Brésil. Esperança, ASPTA, Science Po Grenoble, Estágio de Mestrado, 2015.

PUGEN, B. Dar, receber, retribuir: práticas e prestações socioeconômicas no turismo rural. Santa Cruz, Doutorado em desenvolvimento regional - UNISC, 2015.

RADOMSKY, G. F. W.; SCHNEIDER, S. Nas teias da economia: o papel das redes sociais e da reciprocidade nos processos locais de desenvolvimento. Sociedade e Estado, 22, 249-284, 2007.

SABOURIN, E. Dispositivos coletivos de apoio à produção e dinâmicas territoriais Raízes. Revista de ciências sociais e econômicas, 29 (1-2), 154-165, 2010.

. Os mecanismos de qualificação e certificação como interfaces entre reciprocidade e troca mercantil. In: CONTERATO, M. A.; NIEDERLE, P. A.; TRICHES, R.M.; MARQUES, F. C.; SCHULTZ,G. (Eds). Mercados e agricultura familiar: interfaces, conexões e conflitos. Brasil: Via Sapiens, 2013. p. 190-210.

SABOURIN, E. ; TYUIENON, R. Produits, monnaie et bingo : les marchés ruraux en Nouvelle Calédonie, entre échange et réciprocité. Revue du Mauss, 29 :131-158, 2007.

SCUBLA, L. Logiques de la réciprocité. Paris: Cahiers du Crea,1985.283p.

SERVET, J. M. Le principe de réciprocité chez Karl Polanyi, contribution à une définition de l'économie solidaire. Revue Tiers Monde, 190,2 : 255-273, 2007.

TEMPLE, D. L'économie humaine. La revue du Mauss, 10, (1):103-109, 1997.

. Les structures élémentaires de la réciprocité.Revue du Mauss, 12, 2:234-242, 1998.

.Teoría de la Reciprocidad. La Paz, Bolivia: PADEP/GTZ, 2003.3 Tomes.

TEMPLE, D.; CHABAL, M. La réciprocité ou la naissance des valeurs humaine. Paris: l'Harmattan, 1995. 263p.

THURNWALD, R. Economics in primitive communities. London: Oxford University Press; Paris:Payot, 1937.

YAMPARA, S.; MAMANI, S.; CALANCHA, N. La cosmovisión y lógica en la dinámica socioeconómica del qhatu/feria 16 de julio. La Paz: PIEB, UPEA, CISTEM, 2007.

Artigo recebido em 22/08/2015. Aceito para publicação em 21/09/2015. 